\title{
Consideration of culture in development of home economics curriculum in Nigeria
}

\author{
Uloma Charity Oguzor \\ Department of Home Economics, Federal College of Education, Omoku, Riviers State, Nigeria
}

E-mail address: ozycee24@gmail.com

\section{ABSTRACT}

This paper tries to examine the consideration of culture in the d curriculum in Nigeria. The cultural element which the school draws $m$ include so ety's values, norms, religion, belief, languages, customs e.t.c and other attrib tes ch are tran mitted and local acquired. The role of culture in school should be appre part ry in HomeEconomics curriculum development which is practically oriented sroject that deat ith people's clothing, feeding, housekeeping, e.t.c. This will be a guide towar s helping the teachers of the subject know how to deal students with culural diversity.

Keywords: HomeEconomics; consideration of culture; stud

\section{INTRODUCTION}

The concept of cultur na come with various meaning and definitions by different authors. A vnthesis these meaning will put them as embracing all the activities experience a an indiv al learner under the supervision of the school. Homeeconomics cur culum is refers to the group of courses or planned experiences in the proper sequence designed to $\mathrm{p}, \mathrm{C}$ an individual for curriculum should neglect the following
features:

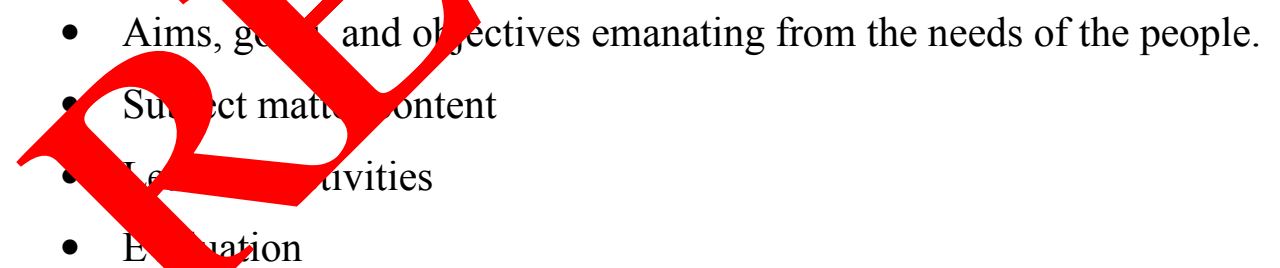

Since the above is the aim of curriculum and culture is about the way of life people therefore, culture should be considered for curriculm development to be success and a effective implementation.curriculum has been viewed as the analysis and study of how schools are created, organized and made to function. The concept and the field of the curriculum therefore should not be limited to the purposes, content and method in educational process. Rather, it should be extended to examine those critical factors in the social-cultural, socia-politicals, social economic, and social ecological environment in which schooling takes place. Consequently, and by it's nature, what constitutes the curriculum s a selection from the 
culture of the society is a critical reflection on the peculiarities of the most stable values of the society, the dynamics of members of the society and portions of the society's cultural heritage that deserves to be propagated.

Culture-curriculum is better understood when conceptualized in a socio-culture contex. in this way, one attempts to analyze and evaluate the schooling process against the influence of the numerous forces or factors in the social envronment bearing in wind that the knowledge which the school transmits derives from sort of ideologists values, philosophies, beliefs and norms all of which are perculiar to various sociao-cultural groups. besides their inabbility, culture therefore, is the nucleus of curriculum in any society.

The cultural elemnts which the school draws from include the society's religion, beliefs, taboos, tradition, language, music, customs, occupations, skill ts, aesthet and other attributes which are society trasmitted and locally acquired ip lud modes problem solving. To this extend, there is nothing that the school teache that does hay a base in that society.

While appreciating the role of culture as the source of schoo no e, it is i prtanr to recognize the fact that these cultural elements are not the same all cultu neit er are they static within culture.

Culture differences among societies may account som bserved differencies in Educational policies and practices in these systems. Si curric $\mathrm{m}$ cannot exit outside the socio-cultural environment, the curriculum plan er/worker should be fully guided by a good knowledge of the culture of the society for wh the curricu um is intended.

According to Urevbu, efforts will be largely w d unless what we teach are relevant to the values of our culture and the resource ataur dispos

Drawing upon some of the theoritical from Dennis Lawton's concept of common culture curriculum,some of the problems of lap thr. Nigeria school curriculum, such as Nigeria school curriculum, such as Nigeria in sility to evolve a philosophy of Education of her own, how to use education t pro ve our iverse societal values: hoe to make judicious selection from the traditional eria ulture and from Anglo american values and resolving the conflict from the diffe o b endend to which psychological theories of learning are plicable tw igeria children, and how to organise the curriculum in stages and sequenc s orther to achieve maximum psychological validity create a significant gap beter the curriculum and reality.

Society a the basis of e ational process. It is the value system of the society that undelies the rmula of edacation purposes. Besides, the various aspects of the culture constitute disc leld of nowledge. Culture therefore produces the needed content for the curricu' It sely the esirable and worth while aspect of the culture for propagation.Thus, the arricu $m$ repro at a continous insight into the life of the society by the school with a vien br

emphasis on aspects of the culture suggest that everything about the culture cannot for in the on how curiculum planner could go about selecting from the culture of society. The model consists of five stages as illustrated below: 
Stage 1

Stage 2

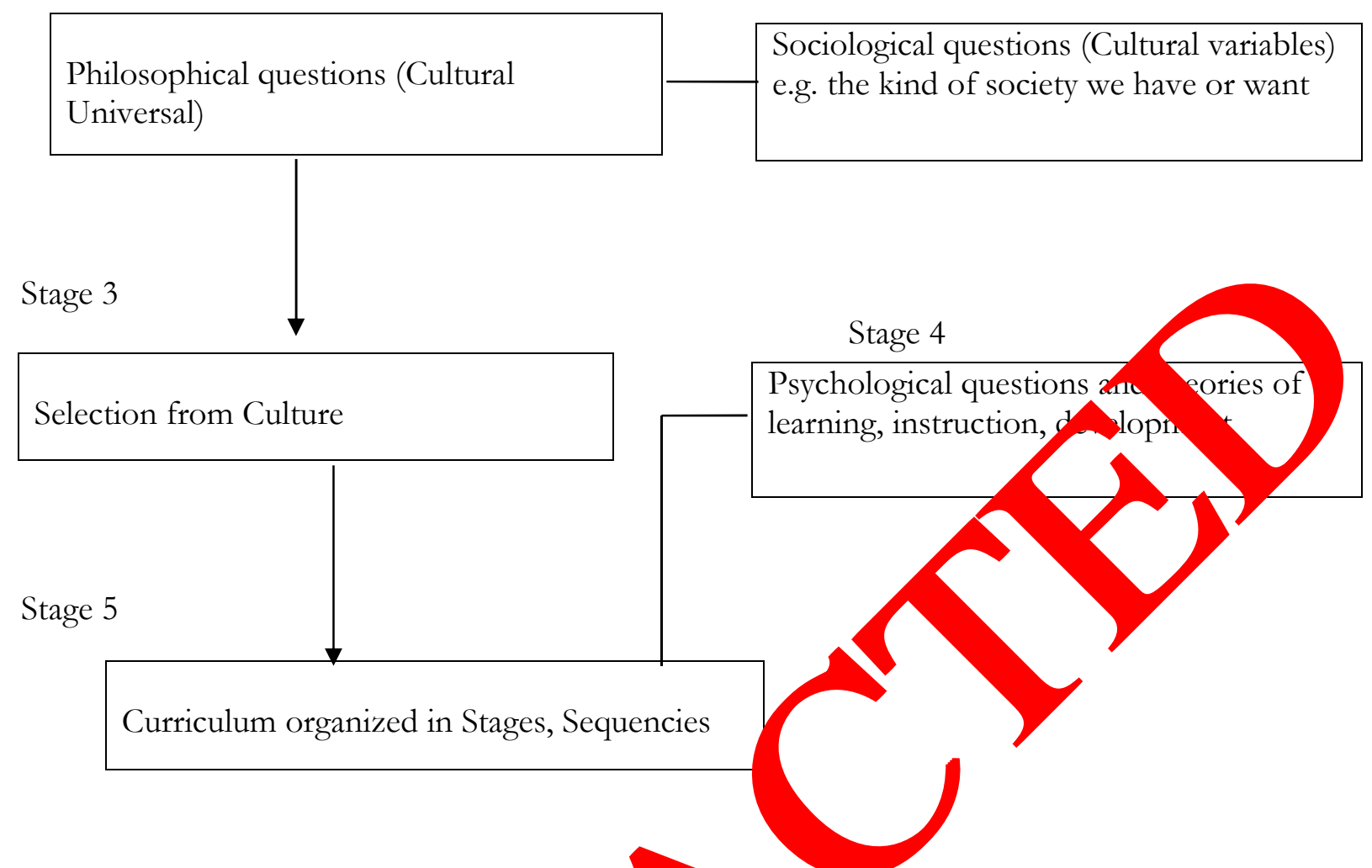

Thereafter, the educational implication experience are explicates and defined as educational purposes. Cultural universal is lik ly t serious problems in a societies such as Nigeria. An example could be drawn from national language policy in Nigeria, which requires secondary schools to te ach me of e pratically oriented subjects such as home economics in the mother tong the tudents or example housa, igbo, and yoruba.

Though the national lic cerm on provides a pleasure justification for this in terms of promoting cu ral herita and national unity, critics are afraid of the political dangers of using the un lum to le rmaate the recognition, dominance of supremacy of three languages. Sre the culture of the society as in stage three, is not an easy task even after all the philosophica sociological question. If education is seen to preserve, transmit and flect cultura heritage of a society, then curiculum may be regarded as a structural serio fearnin experiences extended to individuals through education curiculum design efore, side as a first and basic components needs of the society.

It is orthwh o study society and see its problems, values and needs at any particular tim The tudents /nterest, needs and level of development should be considered by the design Societar needs are subject to change; thus are different times society will have different do. For example,technological improvements have affected home life in such a way that sodrety now needs instruction in the science of homeconomics. Therfore, a curriculul in homeeconomics should increase the basic principles of physic,chemistry and biology.

The objectives of education can be at either national or state level, they may include transmission of culture, establishing national unity, development of the potential of the individual, economic efficiency and self fulfilment.

The objective of homeeconomic education may also fall within this definition. Specifically, objective may describe the standard to be attained to every student following a particular course. Some of the objectives develop for food and nutrition in a syllabus prepared 
at a homeeconomics workshop held at Ibadan in 1972 can better illustrare Bloom's classification of curriculum objectives. The following are some of the objectives:

1. To appreciate the importance of health

2. To teach the priciples of cookery in relation to conserving the nutritive content of foods and to apply those principles to preparation of food locally available foodstuffs.

3. To develop the ability to select a balanced diet from available foods.

The first is from the effective field, the second cognitive psychomotor and the third cognitive capability.

The implication of analysis for the planners of homeeconomics therefore, is that the acquisition of fact,theories and principles and technion sk is need $d$ for success on the practical side of the course. If this dictum is stricly fow owed, It th ore ty help the planners to structure a suitable curriculum to give the student balan educa on.

Curriculum development serves aas an input component for ure there, Is a structural series of intended learning outcome. Curriculy in presch is th results of instruction. It does not prescribe the means i.e the act 1 materia and even the instructional content to be use in achieving the results. ricul indicates what is to be learned, not why or how it should be learned.

When developing the curriculum, the homeec nomics teacher nast use her knowledge of the basic principles of curriculum desgin. She $\mathrm{ml}$ use the relevant curriculum approaches and procedures. Each pattern of curriculum orga tion ado ts a certain idea or scope because it follows certain special criteria for seque. Each partern therefore provides for these charace in a different manner, although they are related.

Some of the approaches to aurriculun in HomeEconomics are: The subject matter approach, integrated curriculum job alysis aproach, the occupational analysis approach competency approach, the mo ap oach e.t.

The subject matters orro conoum a logical and effective method of organizing new knowledge and th fore an tiye method of learning it. By following organized bodies of subject $\mathrm{m}$, ter, tudent $\mathrm{c}_{\mathrm{g}}$, build his store of knowledge more effectively and economically. Interaned cur vlum is a modification of subject curriculum and canbe used effectively in bomefonomics. provide flexibility in meeting students' need and interest and permits grady ion and distribution of course material in keeping with successive levelof compro son as s student gain maturity and understanding.

analys ppr ach includes a number of task. This approach is one of the most ofte used o provi pre and in-service professional trainig to occupational teachers. It's prac en on the knowledge, skills, attitude and judgements that are generally requiro or the successful performance of a task rather than all the components comprising the task.

The modular approach is the unit or standard of measurement. It is the unit of standard of curriculum based on the development of entry level competencies of the students. In the modular desgin the students and their occupational goals from the basis for programme planning. With the modular approach, the total homeeconomics programme divided into unit refered to as modules.

These modules will each take approximately thirty hours of instructional time to achieve with the average group of students. The homeeconoomics desgin has the occupational clusters while developing the curriculum. 
Textile desgninig, distribution and sales

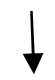

Knitted cardigans, distribution and sales

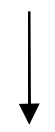

Cake making and sales

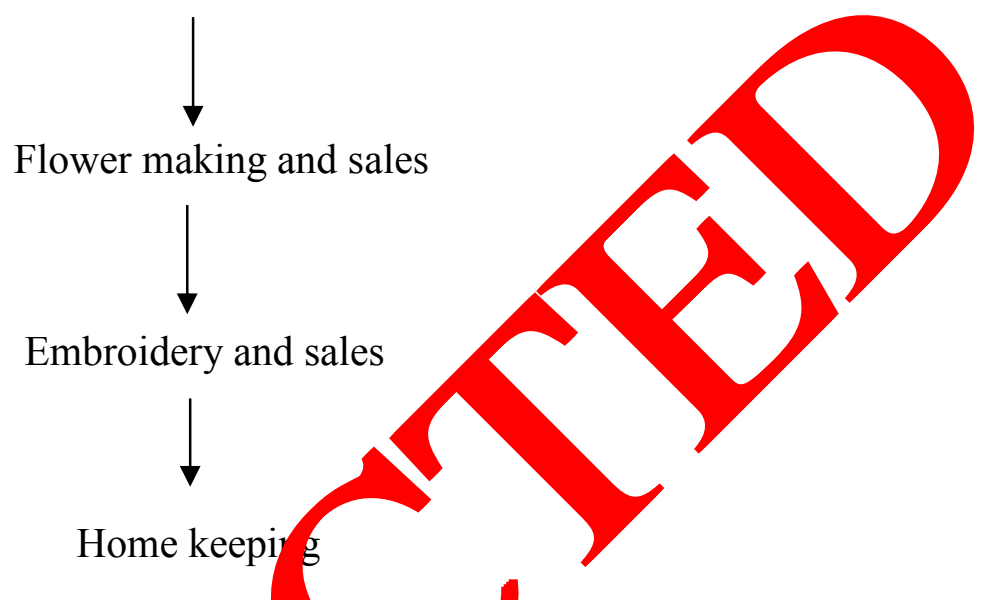

Every student irrespective of the culture wil able to levelop at least to minimun entry level in one homeeconomics occupation. In con the output of one system and input into anot reviculum is a guide to instructional systems which begin with planning.

The mainn aim of homeeconomics pr grammes is to prepare students to become teachers and professionals in $10 \mathrm{mo}$ onomic. The central concern of homeeconomics teacher education should be de elopment of persons who find fulfillment in their commitment to the teachin

The need to trair profession competent homeeconomics teachers has led to the introduction of hom eco ss educaty $n$ at three levels of three levels of the school system. These include hig en eleme v (or grade II) Teacher trainig colleges, Advanced teacher trainig college usually referry $\%$ as college of education. Undergraduate studies in the
universities

\section{Higher Elemen yeve.}

At t level, arainig is geard towards prparing teachers for primary schools. Student wit re mitted into this programme need the minimum qualification of a first school leavin ertincau. Their duration of study depends on the entry level qualification of the students. ase with the primary six or moder school leaving certificate spend a minimum of four(4) yea s, while those who have passed west African school certificate examination take one year to become qualified.

The programme at this level made up of both general and professional education. Students at the end of their course offer subject as geography, history, mathematics and homeeconomics. Thus the programme prepares a student for teaching all subjects in the primary school curriculum. Those who teach homeeconomics after completing their course are perhaps the one who distinguished themselves in the subject while at school especially intrested in it. 


\section{College of Education Level:}

The at studies at this level is geard towards giving professional trainig to a student in one or two particular subjects, which will enable her to teach in secondary schools. Some of the graduates may also teach in the grade II teacher training institutios.

Students admitted in the department of homeeconomics in these institutions take some courses related to homeeconomicsand education alone, and at this stage the training is fairly specialised. The student also experience teaching practice for a minimum period of three months. They must possess a minimum qualification of either West African School Cerfificate with at least four credit in related subjects,especially biology, and ch or needlework and cooking or teacher's GradeII certificate with either credi or mern homeeconomics- related subjects and English or General Certificate of Eduea. (G.C.E) ordinary level. Both categories of students are expected to spend a mini $m$ on ee yer training.

\section{Under Graduate Level:}

The programme at this level is geared toward pre ring tech al skilled and professionally competent teachers of homeeconomics who wil expected 0 teach at the colleges of education. Grade II teacher's college or seco tay scho As mentioned before, homeeconomics education has so far been introdu ed into two or ar universities; The university of Nigeria, Nsukka, University of Ben and Ahmadu Bello University Zaria. These universitties offer a four-year or three-year pr ramme, at the end of which Bachelor of science degree is awarded.

These are the three levels at which heeconom whers are trained at present.

The private sectorsare not left beh a 11 owing curriculum of homeeconomics programme, Furthemore, in order to gain a tr e pow, ge of the standard of homeeconomics education on primary schools, an a will $\mathrm{m}$ te to analyze:

I. The curriculum for prip vs sc bol hom conomics

II. The selection of tear ar mics in the primary school and

III. The programme training the homeeconomics teacher in the secondary schools.

From the curn ulum homeeconomics in Edo State of Nigeria, the theme of the curriculum is se as the child home; in developing this theme to realize the above aims and objective six an s of homeconomics have been identified as sub-theme or units for the curriculum. Ea a is e ected to be taught at particular stage of primary education. These sub-them incluo.

$\begin{array}{lc}\text { B. } & \text { Primary 1-6 } \\ \text { C. }- \text { Fy od and Nutrition } & \text { Primary 3-6 } \\ \text { D. }- \text { Good grooming } & \text { Primary 3-6 } \\ \text { E. }- \text { Home and family living } 3-6 \\ \text { F. -Family and human relation } & \text { Primary 5-6 }\end{array}$


Unit A deals with all six classes while units B,C and D start only in primary three, and units $\mathrm{E}$ and $\mathrm{F}$ in primaries five and six. This arrangement is in recognition of the varying shapes of the child's maturity to ensure that more difficult concepts are introduced at the appropriet stage of development.

The planner advice that the teacher concerned with the use of the syllabus should be originally and resourceful in her lesson planning the contents of the curriculum tend to tally with the set objectives for the classes and are within the chronolgical age and expected performance of the students/pupils.

\section{CULTURE AND CURRICULUM DEVELOPMENT IN HOMEECON MICS}

In many communities today our general society is reflected in the cultural a sity of our classrooms. Whe we refer to students as beeing cultural different are t king those whose racial, nationality, religious, and ethnic characteristic d fin them from the majority. Their speach, manners, attitudes and habits may be distincti They may have backgrounds and personality structure that differ significantly in others.

Culture diversity may present a variety of problen to a cher. The students are exposed to two sets of norms, one set at home and an mos set as schen, these norms pull opposite direction. Other students respond to heir peculiar behaviour with prejudice. Teachers and students may be inclined to treat all $\mathrm{m}$ ubers of a p rticular minority groups, all too often the teacher fails to recognize special proble and pote htialities of an individual.

The culture different helps to becom acquaint in ne community, the homes and families of students, and the individual stuc actures you will be able to identify which minority group are and to what extent.

A large group deserving of an attent 1 is compained of culturally disadvantages families some culturally differe ctan ies may be culturally disadvantaged, but these terms are by no means synonym The major yoblems confronting diadvantaged families include; housing, shortag of a ura toung for low income families, opposition of community associations dindividu to having culturally.

\section{CONCLUS ON}

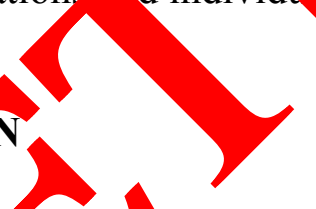

The cult. any ss iety affects its curriculum. Hence, culture includes everthing that can be munt dr $\mathrm{m}$ one generation to it's successor. This involves a whole ways of life astruc re of to ng and peoples heritage which is made up of both material and non nia 1.0 life since that word curriculum has come to be used reference to educa, and is now taken as a councel which students undertakes as they compete for high grades, $p_{a}$ os, certificates or other forms of academics rewards, in addition, there can be no education sithout culture because education is a process that led continuity and meaning to lives. Hence, issue curriculum comes to be used in relation to education, The only general view about it is that it is a programme of studies to be completed by teachers and learners which need to be developed through the influences of the society's culture. 


\section{RECOMENDATION}

Conception and perception of culture in the development of homeeconmics programme should be considered and upgraded. Enough awarnesss should be created to the curriculum planners in the development of homeeconomics programme. The society sholud be encourage to ask psychological and sociological questionns that will imbibe culture in the curriculum of homeeconomics programme. The government should also know that culture of differnt ethnic groups will enhance the teaching/ learning processes of homeeconomics programme, therfore she should allow culture to be paramount in the curriculum planning of homeecomamics progrmme.

\section{References}

[1] Federal Government Syllabus for Grade II Teacher Training, Economics (Lagos, Nigeria, 1974), Pg. 214.

[2] Iyamu E. O (2005). Culture in the development of curri lum

[3] Olaitan S. O (2001). Introduction to the teaching of

[4] Okobiah O. S (1984). "The New National Polic on Education and the Development of social studies curriculum for Nigeria schools" $N$ erian Joury al of curriculum studies, Vol. III, No. 11984.

[5] Onwuka U. (ed). Curriclum Developme 4 frica. Ontsha. African-Feb.

[6] Pratt David (1980). Curriculum Design at 1 Devery nent New York. Harcourt Brace Jov. Inc. 1980.

[7] Tittenbrun J., Internationg etters of Social hd Humanistic Sciences 11 (2013) 10-34.

[8] Tittenbrun J., Internati Lo soulal and Humanistic Sciences 2 (2014) 20-40.

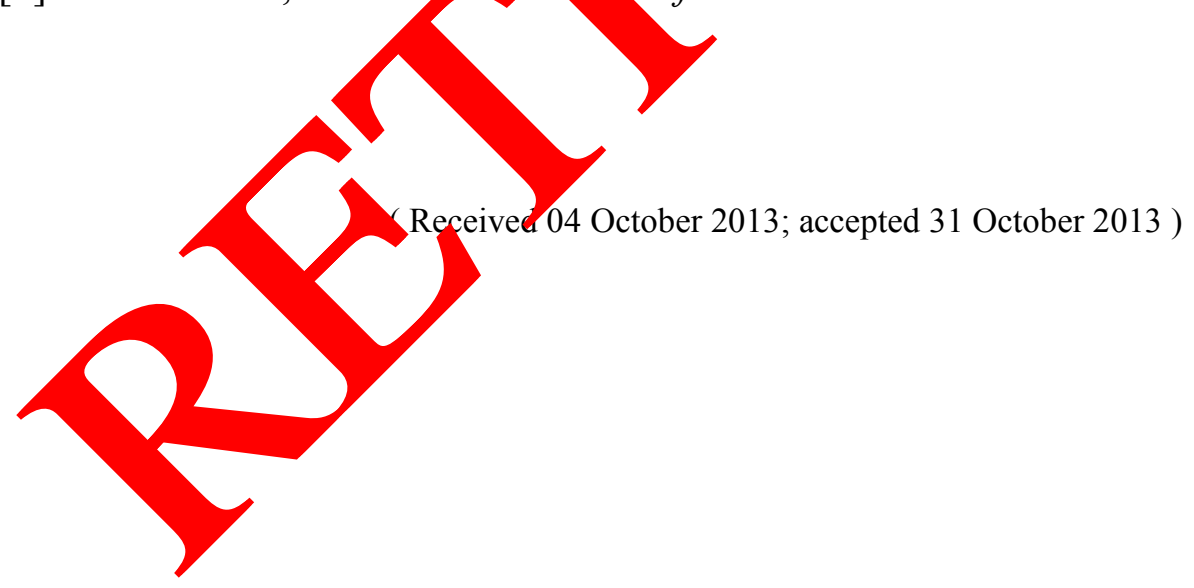

